\title{
Turbidity and Viscosity Measurements on Some Cationic Detergents in Water and in Sodium Chloride Solutions
}

\author{
Lawrence M. Kushner, Willard D. Hubbard, and Rebecca A. Parker
}

\begin{abstract}
Light-scattering and viscosity measurements were made on solutions of three cationic detergents in distilled water and in various solutions of sodium chloride. The detergents were dodecylamine hydrochloride, dodecyltrimethylammonium chloride, and tetradecyltrimethylammonium chloride. The first of these was investigated at $30^{\circ} \mathrm{C}$ and the others at $23^{\circ} \mathrm{C}$. The micellar weight and the intrinsic viscosity of the micelles of each detergent were calculated, and the dependence of these quantities on the concentration of sodium chloride is discussed.
\end{abstract}

\section{Introduction}

The anionic detergent sodium dodecyl sulfate has been the subject of a number of physical chemical investigations. Studies have been made on dilute aqueous solutions of the detergent with respect to light scattering $[1,2],{ }^{1}$ viscosity [3], and electrophoresis [4]. As a result, the micellar behavior of the material has been well characterized.

A particularly interesting feature of these investigations is the marked dependence of the physical property being measured (turbidity, viscosity, etc.) on the quantity of simple electrolyte in the solutions. In the case of light-scattering measurements, it is found that the addition of sodium chloride up to a concentration of about 0.05 to $0.06 \mathrm{M}$ causes a large increase in the turbidity of the solutions. Accordingly, the micellar weight calculated from the data by the method of Debye [5] or Mysels [6] increases rapidly with increasing salt concentration in this range. The relative viscosity of the solutions decreases markedly in the presence of similar concentrations of simple electrolyte. This is reflected in the intrinsic viscosity which decreases rapidly in precisely the same range.

This paper describes the results of turbidity and viscosity measurements made on solutions of three cationic detergents in distilled water and in solutions of sodium chloride. Dodecylamine hydrochloride was chosen because its surface active ion is the positively charged analog of the dodecyl sulfate ion. Because of the poor solubility of the primary amine hydrochloride in salt solutions, measurements were also made on a comparable quaternary salt, dodecyltrimethylammonium chloride. Tetradecyltrimethylammonium chloride was investigated to give an indication of the effect of increasing the chain length of the hydrophobic portion of the surface active ion.

1 Figures in brackets indicate the literature references at the end of this paper.

\section{Experimental Procedure}

\subsection{Materials}

Dodecylamine hydrochloride was prepared from dodecylamine in the following manner. Fifty grams of dodecylamine (Armour \& Co.) was dissolved in anhydrous benzene. Gaseous hydrogen chloride was bubbled through the solution until a slight excess, as indicated by a methyl redspot test, had been added. The solution was cooled to approximately $0^{\circ} \mathrm{C}$, and the dodecylamine hydrochloride crystals were filtered off at that temperature. The material was then recrystallized twice in the same manner from benzene and finally dried overnight in a vacuum oven at $60^{\circ} \mathrm{C}$. As a check on the purity of the salt, the specific conductance of a $0.01354-N$ aqueous solution was determined at $30^{\circ} \mathrm{C}$. A value of $13.62 \times 10^{-4} \mathrm{ohm}^{-1}$ was obtained. This is to be compared with the value $13.64 \times 10^{-4} \mathrm{ohm}^{-1}$ given by Armour \& Co. The chloride content was determined to be 15.96 percent. The theoretical value is 15.99 percent.

Subsequent measurements of the turbidity of aqueous solutions of the dodecylamine hydrochloride indicated the presence of traces of a water-insoluble impurity, suspected to be benzene. Two recrystallizations of the salt from cold methyl alcohol eliminated the contaminant.

Dodecyltrimethylammonium chloride and tetradecyltrimethylammonium chloride were obtained as the quaternary salts from Armour \& Co. Both were purified by precipitating them from solutions of ethanol by the addition of anhydrous ethyl ether. The resulting slurry was cooled as before, and the crystals were removed by filtration. They were then dried under vacuum at room temperature.

\subsection{Refractive Index}

Measurements of the refractive-index increments $(\Delta n / \Delta c)$ of the three detergents in distilled water and 
TABLE 1. Light-scattering and viscosity data for solutions of dodecylamine hydrochloride, dodecyltrimethylammonium chloride, and tetradecyltrimethylammonium chloride in distilled water and in solutions of sodium chloride

$(\mathrm{cp}=$ centipoise $[\eta]=$ intrinsic viscosity; $\Delta n / \Delta c=$ refractive index increment; CMC=critical micelle concentration; $[Z]=$ intrinsic dissymmetry)

\begin{tabular}{|c|c|c|c|c|c|c|c|c|}
\hline \multicolumn{9}{|c|}{ DODECYLAMINE HYDROCHLORIDE $\left(30^{\circ} \mathrm{C}\right)$} \\
\hline Solvent & $\begin{array}{c}\text { Concentra- } \\
\text { tion }\end{array}$ & Density & Viscosity & {$[\eta]$} & $\begin{array}{c}\text { Concentra- } \\
\text { tion }\end{array}$ & Turbidity & $\Delta n / \Delta c$ & $\begin{array}{l}\text { Micellar } \\
\text { weight }\end{array}$ \\
\hline $\begin{array}{l}\text { Distilled } \mathrm{H}_{2} \mathrm{O} \\
\mathrm{CMC}=0.323 \mathrm{~g} / \mathrm{dl}\end{array}$ & $\left\{\begin{array}{l}g / d l \\
0 \\
0.100 \\
.200 \\
.300 \\
.400 \\
.500 \\
.600 \\
.800 \\
1.000 \\
1.100 \\
1.200\end{array}\right.$ & $\begin{array}{c}g / m l \\
0.99565 \\
.99556 \\
.99548 \\
.99539 \\
.99531 \\
.99523 \\
.99515 \\
.99498 \\
.99482 \\
.99473 \\
.99465 \\
\end{array}$ & $\begin{array}{c}c p \\
0.7975 \\
8060 \\
.8095 \\
.8148 \\
.8189 \\
.8327 \\
.8466 \\
.8519 \\
.8592 \\
\end{array}$ & 0.064 & $\left\{\begin{array}{c}g / m l \times 10^{2} \\
0 \\
0.089 \\
.222 \\
.295 \\
.343 \\
.363 \\
.400 \\
.439 \\
.505 \\
.561 \\
.680 \\
.800 \\
.907 \\
.927 \\
1.027 \\
1.188 \\
1.428 \\
1.648 \\
\\
0 \\
0.075 \\
.121 \\
.190 \\
.218 \\
.275 \\
.320 \\
.410 \\
.510 \\
.610 \\
.735 \\
.815 \\
1.015 \\
1.215\end{array}\right.$ & $\begin{array}{c}\mathrm{cm}^{-1} \times 10^{5} \\
4.76 \\
5.00 \\
4.95 \\
5.33 \\
6.95 \\
7.81 \\
12.23 \\
15.28 \\
20.42 \\
24.18 \\
31.42 \\
38.70 \\
40.08 \\
40.89 \\
43.03 \\
45.17 \\
48.60 \\
51.31 \\
\\
4.90 \\
5.14 \\
5.09 \\
5.47 \\
5.38 \\
5.95 \\
12.00 \\
21.13 \\
29.04 \\
34.84 \\
40.41 \\
43.32 \\
49.46 \\
54.36\end{array}$ & $m l / g$ & 17,800 \\
\hline $\begin{array}{l}0.02-M \mathrm{NaCl} \\
\mathrm{C} \mathrm{MC}=0.227 \mathrm{~g} / \mathrm{dl}\end{array}$ & $\left\{\begin{array}{r}0 \\
0.100 \\
.200 \\
.300 \\
.400 \\
.500 \\
.600 \\
.800 \\
1.000 \\
\end{array}\right.$ & $\begin{array}{r}0.99646 \\
.99638 \\
.99630 \\
.99621 \\
.99613 \\
.99605 \\
.99596 \\
.99580 \\
.99563 \\
\end{array}$ & $\begin{array}{r}0.7990 \\
.8037 \\
.8075 \\
.8118 \\
.8161 \\
.8205 \\
.8298 \\
.8397 \\
\end{array}$ & 0.048 & $\left\{\begin{array}{r}0 \\
0.123 \\
.268 \\
.300 \\
.400 \\
.500 \\
.600 \\
.700 \\
.800 \\
.900 \\
1.000 \\
1.100 \\
1.250\end{array}\right.$ & $\begin{array}{r}4.76 \\
5.24 \\
12.42 \\
17.37 \\
30.5 \\
40.1 \\
48.1 \\
55.2 \\
61.4 \\
66.6 \\
71.9 \\
76.6 \\
83.3\end{array}$ & 0.160 & 24,100 \\
\hline $\begin{array}{l}0.04-M \mathrm{NaCl} \\
\mathrm{CMC}=0.165 \mathrm{~g} / \mathrm{dl}\end{array}$ & $\left\{\begin{array}{r}0 \\
0.100 \\
.200 \\
.300 \\
.400 \\
.500 \\
.600 \\
.800 \\
1.000 \\
\\
\end{array}\right.$ & $\begin{array}{r}0.99725 \\
.99717 \\
.99709 \\
.99702 \\
.99694 \\
.99686 \\
.99678 \\
.99663 \\
.99647 \\
\end{array}$ & $\begin{array}{r}0.8006 \\
.8048 \\
.8051 \\
.8089 \\
.8114 \\
.8159 \\
.8199 \\
.8287 \\
.8393 \\
\end{array}$ & 0.039 & $\left\{\begin{array}{r}0 \\
0.103 \\
.187 \\
.200 \\
.300 \\
.400 \\
.500 \\
.600 \\
.700 \\
.800 \\
.900 \\
1.000 \\
1.100 \\
1.200 \\
1.250\end{array}\right.$ & $\begin{array}{r}5.24 \\
5.38 \\
10.57 \\
12.99 \\
30.5 \\
45.2 \\
58.5 \\
70.8 \\
81.6 \\
91.7 \\
101.2 \\
110.4 \\
120.0 \\
129.0 \\
133.8\end{array}$ & 0.160 & 28,200 \\
\hline $\begin{array}{l}0.06-M \mathrm{NaCl} \\
\mathrm{C} \mathrm{MC}=0.145 \mathrm{~g} / \mathrm{dl}\end{array}$ & $\left(\begin{array}{r}0 \\
0.100 \\
.200 \\
.300 \\
.400 \\
.500 \\
.600 \\
.800 \\
1.000 \\
\\
\end{array}\right.$ & $\begin{array}{r}0.99807 \\
.99798 \\
.99789 \\
.99780 \\
.99771 \\
.99762 \\
.99752 \\
.99734 \\
.99716 \\
\end{array}$ & $\begin{array}{r}0.8021 \\
.8091 \\
.8071 \\
.8104 \\
.8136 \\
.8186 \\
.8226 \\
.8304 \\
.8399 \\
\end{array}$ & 0.034 & $\begin{array}{r}0 \\
0.101 \\
.200 \\
.300 \\
.400 \\
.500 \\
.650 \\
.750 \\
.800 \\
.900 \\
1.000 \\
1.050 \\
1.100 \\
1.250\end{array}$ & $\begin{array}{l}5.24 \\
5.24 \\
20.8 \\
42.8 \\
62.8 \\
80.4 \\
105.7 \\
121.9 \\
129.5 \\
145 \\
158 \\
165 \\
171 \\
191\end{array}$ & 0.160 & 34,000 \\
\hline
\end{tabular}

in the sodium chloride solutions were made with a differential refractometer similar to that described by P. P. Debye [7]. All measurements were made at $23^{\circ} \mathrm{C}$, using blue light $(436 \mathrm{~m} \mu)$. The refractiveindex increments determined are given in table 1 .

\subsection{Turbidity}

Measurements of turbidity were made in semioctagonal cells in an absolute light-scattering photometer [8]. Semioctagonal cells were used so that determinations of dissymmetry, $Z$ (the ratio of the 
TABLE 1. Light-scattering and viscosity data for solutions of dodecylamine hydrochloride, dodecyltrimethylammonium chloride, and tetradecyltrimethylammonium chloride in distilled water and in solutions of sodium chloride-Continued

$(\mathrm{cp}=$ centipoise $[\eta]=$ intrinsic viscosity; $\Delta n / \Delta \mathrm{c}=$ refractive index increment; $\mathrm{C} M \mathrm{C}=$ critical micelle concentration; $[Z]=$ intrinsic dissymmetry)

\begin{tabular}{|c|c|c|c|c|c|c|c|c|}
\hline Solvent & $\begin{array}{c}\text { Concentra- } \\
\text { tion }\end{array}$ & Density & Viscosity & {$[\eta]$} & $\begin{array}{c}\text { Concentra- } \\
\text { tion }\end{array}$ & Turbidity & $\Delta n / \Delta c$ & $\begin{array}{l}\text { Micellar } \\
\text { weight }\end{array}$ \\
\hline $\begin{array}{c}0.08-M \mathrm{NaCl} \\
\mathrm{CMC}=0.118 \mathrm{~g} / \mathrm{dl}\end{array}$ & $\left\{\begin{array}{l}g / d l \\
0 \\
0.100 \\
.200 \\
.300 \\
.400 \\
.500 \\
.600 \\
.800 \\
1.000\end{array}\right.$ & $\begin{array}{c}g / m l \\
0.99890 \\
.99881 \\
.99873 \\
.99864 \\
.99855 \\
.99846 \\
.99838 \\
.99820 \\
.99803\end{array}$ & $\begin{array}{c}c p \\
0.8036 \\
.8057 \\
.8085 \\
.8124 \\
.8165 \\
.8207 \\
.8254 \\
.8355 \\
.8479 \\
\end{array}$ & 0.038 & $\left\{\begin{array}{c}g / m l \times 10^{2} \\
0 \\
0.037 \\
.097 \\
.155 \\
.200 \\
.300 \\
.340 \\
.461 \\
.612 \\
.794 \\
.926 \\
1.000\end{array}\right.$ & $\begin{array}{c}\mathrm{cm}^{-1} \times 10^{5} \\
5.24 \\
5.14 \\
5.28 \\
17.47 \\
32.8 \\
67.8 \\
81.4 \\
122 \\
167 \\
222 \\
261 \\
283\end{array}$ & $m l / g$ & 51,100 \\
\hline $\begin{array}{c}0.10-M \mathrm{NaCl} \\
\mathrm{C} \mathrm{MC}=0.109 \mathrm{~g} / \mathrm{dl}\end{array}$ & $\left\{\begin{array}{r}0 \\
0.100 \\
.200 \\
.300 \\
.400 \\
.500 \\
.600 \\
.800 \\
1.000 \\
\end{array}\right.$ & $\begin{array}{r}0.99972 \\
.99964 \\
.99955 \\
.99946 \\
.99938 \\
.99929 \\
.99921 \\
.99904 \\
.99887 \\
\end{array}$ & $\begin{array}{r}0.8049 \\
.8069 \\
.8094 \\
.8148 \\
.8202 \\
.8260 \\
.8327 \\
.8484 \\
.838 \\
\end{array}$ & 0.044 & $\left\{\begin{array}{l}0 \\
0.099 \\
.150 \\
.315 \\
.385 \\
.490 \\
.585 \\
.755 \\
.880 \\
.970 \\
1.000\end{array}\right.$ & $\begin{array}{c}5.42 \\
5.47 \\
31.9 \\
127.6 \\
167 \\
225 \\
284 \\
381 \\
454 \\
506 \\
524\end{array}$ & 0.160 & 85,500 \\
\hline $\begin{array}{c}0.15-M \mathrm{NaCl} \\
\mathrm{C} \mathrm{MC}=0.101 \mathrm{~g} / \mathrm{dl}\end{array}$ & $\left\{\begin{array}{r}0 \\
0.100 \\
.200 \\
.300 \\
.400 \\
.500 \\
.600 \\
.800 \\
1.000 \\
\end{array}\right.$ & $\begin{array}{l}1.00178 \\
1.00169 \\
1.00159 \\
1.00149 \\
1.00137 \\
1.00130 \\
1.00120 \\
1.00101 \\
1.00081\end{array}$ & $\begin{array}{r}0.8090 \\
.8108 \\
.8167 \\
.8261 \\
.8384 \\
.8528 \\
.8694 \\
.9101 \\
.9638 \\
\end{array}$ & 0.060 & $\left\{\begin{array}{r}0 \\
0.050 \\
.074 \\
.107 \\
.130 \\
.205 \\
.330 \\
.480 \\
.592 \\
.780 \\
.916 \\
1.000\end{array}\right.$ & $\begin{array}{r}5.38 \\
5.47 \\
5.52 \\
11.57 \\
47.6 \\
162.8 \\
353 \\
558 \\
700 \\
919 \\
1076 \\
1176\end{array}$ & 0.160 & 231,000 \\
\hline $\begin{array}{c}0.20-M \mathrm{NaCl} \\
\mathrm{C} . \mathrm{MC}=0.093 \mathrm{~g} / \mathrm{dl}\end{array}$ & $\left\{\begin{array}{r}0 \\
0.100 \\
.200 \\
.300 \\
.400 \\
.500 \\
.600 \\
.800 \\
1.000\end{array}\right.$ & $\begin{array}{l}1.00367 \\
1.00359 \\
1.00350 \\
1.00342 \\
1.00333 \\
1.00324 \\
1.00316 \\
1.00298 \\
1.00281\end{array}$ & $\begin{array}{r}0.8129 \\
.8167 \\
.8350 \\
.8610 \\
.8966 \\
.9401 \\
.9909 \\
1.1204 \\
1.2965 \\
\end{array}$ & 0.15 & $\left\{\begin{array}{r}0 \\
0.050 \\
.107 \\
.171 \\
.281 \\
.408 \\
.667 \\
.769 \\
.901 \\
1.000\end{array}\right.$ & $\begin{array}{c}5.52 \\
5.52 \\
61.9 \\
346 \\
743 \\
1257 \\
1950 \\
2220 \\
2550 \\
2750\end{array}$ & 0.160 & 655,000 \\
\hline $\begin{array}{c}0.25-M \mathrm{NaCl}^{2} \\
\mathrm{CMC}=0.093 \mathrm{~g} / \mathrm{dl}\end{array}$ & $\left\{\begin{array}{l}0 \\
0.100 \\
.200 \\
.300 \\
.400 \\
.600 \\
.800\end{array}\right.$ & $\begin{array}{l}1.00580 \\
1.00570 \\
1.00559 \\
1.00548 \\
1.00537 \\
\text { 1. } 00516 \\
\text { 1. } 00494\end{array}$ & $\begin{array}{r}0.8156 \\
.8270 \\
.8670 \\
.9230 \\
1.0060 \\
1.2701 \\
1.7631\end{array}$ & 0.33 & \multicolumn{2}{|c|}{$[7] \simeq 1.20$} & & $\sim 1,125,000$ \\
\hline $\begin{array}{c}0.30-M \mathrm{NaCl} \\
\mathrm{CMC}=0.085 \mathrm{~g} / \mathrm{dl}\end{array}$ & $\left\{\begin{array}{l}0 \\
0.100 \\
.200 \\
.300 \\
.400 \\
.500\end{array}\right.$ & $\begin{array}{l}1.00785 \\
1.00772 \\
1.00758 \\
1.00745 \\
1.00731 \\
1.00717\end{array}$ & $\begin{array}{r}0.8201 \\
.8384 \\
.9102 \\
\text { 1. } 0446 \\
\text { 1. } 2909 \\
\text { 1. } 6907\end{array}$ & 0.45 & \multicolumn{2}{|c|}{$[7] \simeq 1.40$} & & $\sim 1,800,090$ \\
\hline \multicolumn{9}{|c|}{ DODECYLTRIMETHYLAMMONIUM CHLORIDE $\left(23^{\circ} \mathrm{C}\right)$} \\
\hline $\begin{array}{c}\text { Distilled } \mathrm{H}_{2} \mathrm{O} \\
\mathrm{CMC}=0.570 \mathrm{~g} / \mathrm{dl}\end{array}$ & $\left\{\begin{array}{l}0 \\
0.404 \\
.508 \\
.607 \\
.708 \\
.800 \\
1.013 \\
1.202 \\
1.402 \\
\end{array}\right.$ & $\begin{array}{r}0.99754 \\
.99703 \\
.99703 \\
.99698 \\
.99687 \\
.99678 \\
.99655 \\
.99636 \\
.99615 \\
\end{array}$ & $\begin{array}{r}0.9323 \\
.9491 \\
.9515 \\
.9546 \\
.9588 \\
.9631 \\
.9744 \\
.8853 \\
.9974 \\
\end{array}$ & 0.040 & $\begin{array}{r}0.183 \\
.225 \\
.427 \\
.478 \\
.545 \\
.620 \\
.709 \\
.793 \\
.955 \\
1.092 \\
1.197\end{array}$ & $\begin{array}{r}5.47 \\
5.62 \\
5.66 \\
5.71 \\
5.71 \\
8.81 \\
13.09 \\
16.66 \\
21.75 \\
25.09 \\
26.89\end{array}$ & 0.156 & 9,900 \\
\hline
\end{tabular}

scattered intensity at $45^{\circ}$ to that at $135^{\circ}$ ), could be made as a check on the cleanliness of the solutions. The solvents, distilled water or solutions of sodium chloride, were easily obtained with no dissymmetry by filtering two or three times through ultrafine fritted glass or porcelain filters. Solutions of increas- ing concentration were prepared by the addition of a known weight of detergent crystals to clean solvent or solution already in the light-scattering cell. After the detergent crystals had dissolved, the solution was filtered a number of times until the dissymmetry was at an acceptably low level. Except for dodecyl- 
TABLE 1. Light-scattering and viscosity data for solutions of dodecylamine hydrochloride, dodecyltrimethylammonium chloride, and tetradecyltrimethylammonium chloride in distilled water and in solutions of sodium chloride - Continued

$(\mathrm{cp}=$ centipoise $[\eta]=$ intrinsic viscosity; $\Delta n / \Delta c=$ refractive index increment; CMC=critical micelle concentration; $[Z]=$ intrinsic dissymmetry).

\begin{tabular}{|c|c|c|c|c|c|c|c|c|}
\hline Solvent & $\begin{array}{c}\text { Concentra- } \\
\text { tion }\end{array}$ & Density & Viscosity & {$[\eta]$} & $\begin{array}{c}\text { Concentra- } \\
\text { tion }\end{array}$ & Turbidity & $\Delta n / \Delta c$ & $\begin{array}{l}\text { Micellar } \\
\text { weight }\end{array}$ \\
\hline $\begin{array}{l}0.02-M \mathrm{NaCl} \\
\mathrm{C} \mathrm{MC}=0.420 \mathrm{~g} / \mathrm{dl}\end{array}$ & 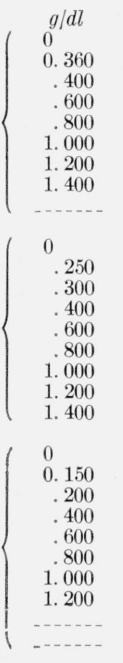 & $\begin{array}{l}g / m l \\
0.99825 \\
.99791 \\
.99789 \\
.99774 \\
.99755 \\
.99737 \\
.99717 \\
.99698 \\
. . \\
0.99914 \\
.99882 \\
.99880 \\
.99874 \\
.99855 \\
.99836 \\
.99817 \\
.99799 \\
.99780 \\
\\
1.00149 \\
1.00134 \\
1.00130 \\
1.00113 \\
1.00096 \\
1.00079 \\
1.00062 \\
1.00045 \\
\ldots . . \\
\ldots\end{array}$ & $\begin{array}{c}c p \\
0.9329 \\
.9471 \\
.9483 \\
.9556 \\
.9647 \\
.9743 \\
.9839 \\
.9937 \\
-.934 \\
0.9349 \\
.9452 \\
.9466 \\
.9491 \\
.9571 \\
.9653 \\
.9744 \\
.9831 \\
.9923 \\
\\
0.9399 \\
.9459 \\
.9476 \\
.9540 \\
.9621 \\
.9697 \\
.9779 \\
.9859 \\
--- \\
---\end{array}$ & 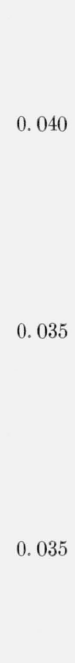 & $\begin{array}{l}g / m l \times 10^{2} \\
0 \\
0.390 \\
.431 \\
.478 \\
.583 \\
.737 \\
.935 \\
1.139 \\
1.249 \\
0 \\
0.179 \\
.323 \\
.373 \\
.478 \\
.638 \\
.765 \\
.890 \\
1.084 \\
0 \\
0.144 \\
.204 \\
.251 \\
.342 \\
.445 \\
.550 \\
.738 \\
.926 \\
1.048\end{array}$ & $\begin{array}{c}c m^{-1} \times 10^{5} \\
4.81 \\
5.52 \\
6.24 \\
9.14 \\
15.4 \\
22.8 \\
30.9 \\
37.8 \\
41.4 \\
\\
4.81 \\
5.43 \\
6.52 \\
9.71 \\
17.1 \\
27.0 \\
34.3 \\
41.2 \\
50.9 \\
\\
5.05 \\
5.24 \\
6.71 \\
11.4 \\
20.3 \\
29.5 \\
38.2 \\
50.8 \\
62.9 \\
71.1\end{array}$ & $m l / g$ & 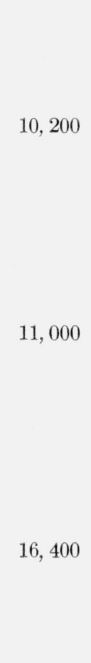 \\
\hline \multicolumn{9}{|c|}{ TETRADECYLTRIMETHYLAMMONIUM CHLORIDE $\left(23^{\circ} \mathrm{C}\right)$} \\
\hline $\begin{array}{l}\text { Distilled } \mathrm{H}_{2} \mathrm{O} \\
\mathrm{CMC}=0.120 \mathrm{~g} / \mathrm{dl}\end{array}$ & 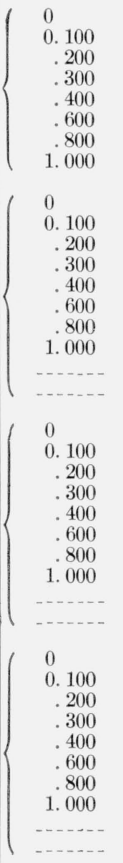 & 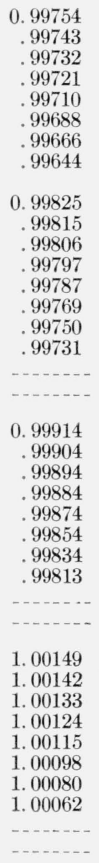 & 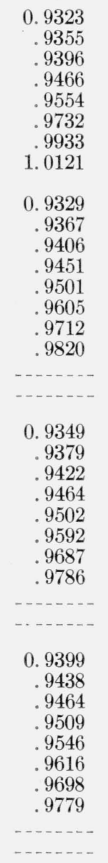 & 0.040 & 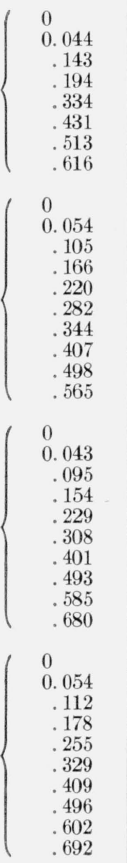 & $\begin{array}{r}4.81 \\
5.00 \\
6.47 \\
9.43 \\
14.9 \\
17.8 \\
19.2 \\
20.8 \\
\\
4.81 \\
5.14 \\
10.1 \\
17.0 \\
22.7 \\
28.3 \\
32.6 \\
37.2 \\
42.7 \\
45.2 \\
\\
4.72 \\
5.52 \\
12.5 \\
20.3 \\
29.5 \\
38.3 \\
47.1 \\
55.0 \\
63.3 \\
69.3 \\
4.90 \\
9.76 \\
18.8 \\
28.7 \\
39.4 \\
50.6 \\
61.3 \\
72.1 \\
84.7 \\
93.4\end{array}$ & 0.157 & 21,800 \\
\hline
\end{tabular}

amine hydrochloride in the presence of high concentrations of sodium chloride, a small dissymmetry, generally 1.05 or less, was observed. In the case of dodecylamine hydrochloride, the dissymmetries observed are caused by the presence of very large micellar structures and are of significance. This is discussed further in a later section.
Because of the low solubility of dodecylamine hydrochloride in salt solutions at $23^{\circ} \mathrm{C}$, the turbidity measurements on it were made at $30^{\circ} \mathrm{C}$. All other turbidity measurements were made at $23^{\circ} \mathrm{C}$. The $436-\mathrm{m} \mu$ line of a mercury-arc lamp was used throughout. 


\subsection{Viscosity}

The experimental details and necessary corrections to be applied to the measured efflux time have been described previously [3]. The only change in procedure was the use of smaller pycnometers for the density determinations [9]. The measurements on the dodecylamine hydrochloride solutions were made at $30^{\circ} \mathrm{C}$. All others were made at $23^{\circ} \mathrm{C}$.

\section{Results and Discussion}

All of the pertinent experimental data are given in table 1. Typical plots of turbidity and viscosity as a function of detergent concentration at various concentrations of sodium chloride are shown in figures 1 and 2. The pronounced effect of the addition of sodium chloride is evident in both figures.

In order to evaluate the micellar weight from the turbidity data, and the intrinsic viscosity of the micelles from the viscosity data, it is necessary to evaluate the critical micelle concentration of the detergent in each of the solvents used. Debye [5] has shown that this can be obtained conveniently from the dependence of the turbidity on concentration (cf. fig. 1). The detergent concentration at which the turbidity begins to increase rapidly clearly represents the concentration at which aggregation of the individual detergent molecules or ions into micelles is beginning to occur to a significant extent. These concentrations, as obtained from the turbidity data, have been chosen as the critical micelle concentration, and are given in table 1 . The dependence of the critical micelle concentration of each detergent on the amount of sodium chloride present is shown in figure 3 . The data reported by Corrin and Harkins (dye titration method) [10] for dodecylamine hydrochloride at $26 \pm 2^{\circ} \mathrm{C}$ are also shown. It is seen that the quaternary dodecylammonium chloride has a much larger critical micelle concentration than does the corresponding primary amine salt. This is simply another manifestation of the greater degree of ionization of the quaternary salt. The addition of two $\mathrm{CH}_{2}$ groups to the long hydrocarbon chain of the surface active ion, as in tetradecyltrimethylammonium chloride,

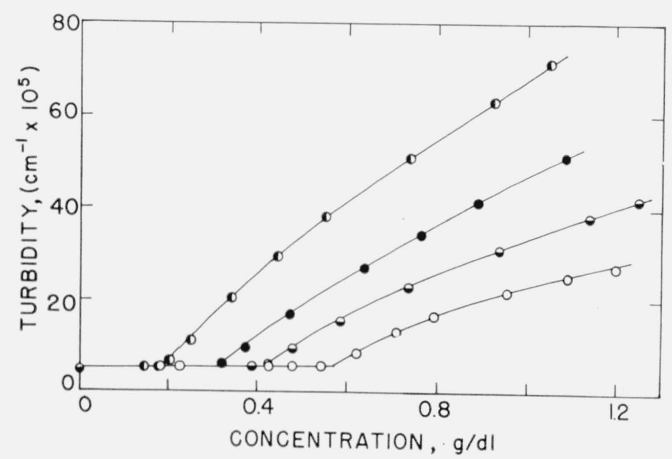

FIGURE 1. Dependence of the turbidity on the concentration of dodecyltrimethylammonium chloride in water $(\bigcirc)$ and in various sodium chloride solutions.

๑, $0.02 \mathrm{M} ; \bullet, 0.04 \mathrm{M} ; \boldsymbol{\bullet}, 0.10 \mathrm{M}$. increases the hydrophobic nature of the ion and results in a lower critical micelle concentration.

The intrinsic viscosity of the micelles was obtained from plots of the experimental data according to eq (1).

$$
\frac{\left(\eta_{\mathrm{rel}}-1\right)}{C_{\mathrm{m}}}=[\eta]+A C_{\mathrm{m}}
$$

$[\eta]$ is the intrinsic viscosity. $C_{\mathrm{m}}$ is the concentration of micelles in grams per deciliter and is assumed to be equal to the total concentration of detergent

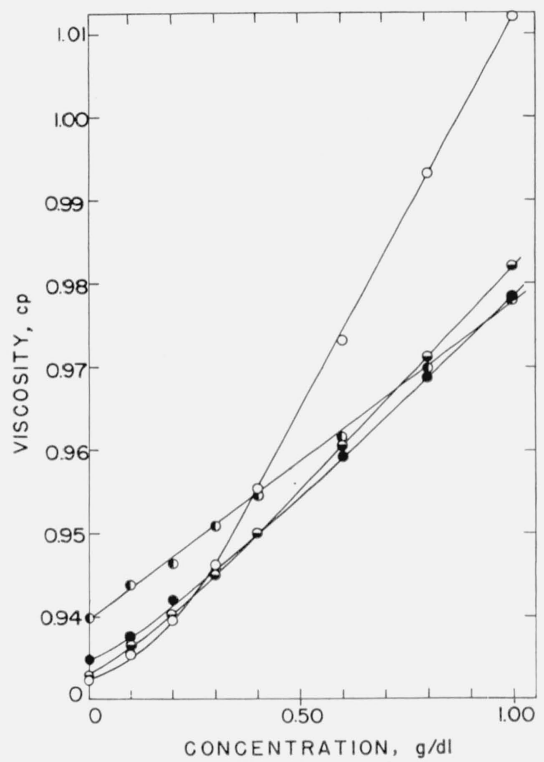

Figure 2. Dependence of the viscosity on the concentration of tetradecyltrimethylammonium chloride in water (O) and in various sodium chloride solutions.

๑, $0.02 \mathrm{M} ; \bullet, 0.04 \mathrm{M} ; \boldsymbol{\bullet}, 0.10 \mathrm{M}$.

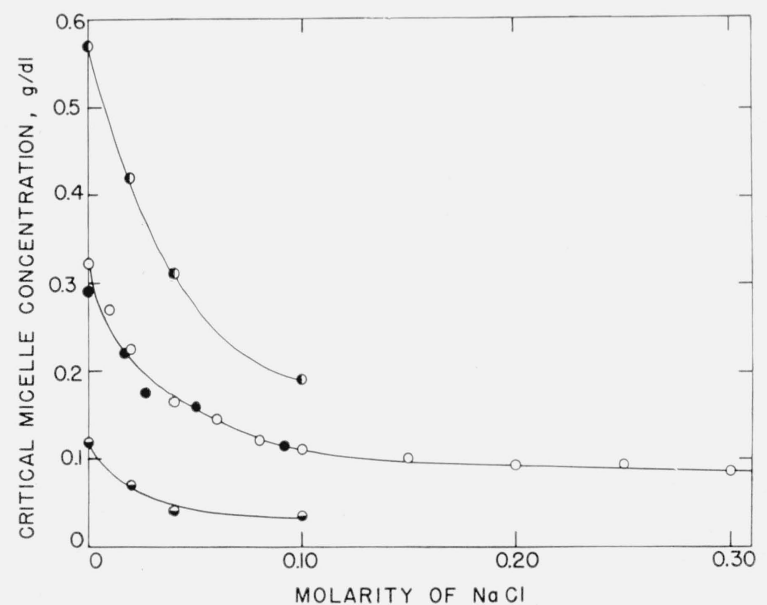

FIGURE 3. Dependence of the critical micelle concentration of dodecyltrimethylammonium chloride $(\mathbf{O})$, dodecylamine hydrochloride $(\bigcirc)$, and tetradecyltrimethylammonium chloride $(-)$ on the concentration of sodium chloride in aqueous solutions.

- data of Corrin and Harkins [10] for dodecylamine hydrochloride at $26^{\circ} \mathrm{C}$. 
minus the critical micelle concentration. $\eta_{\mathrm{rel}}$ is the viscosity of a solution of concentration $C_{\mathrm{m}}$ relative to the viscosity at the critical micelle concentration (i. e., at $C_{\mathrm{m}}=0$ ). The constant $A$ is related to hydrodynamic interactions in the solution. The relationship between $[\eta]$ and a shape factor, $K$, for suspended particles of density $d$, is

$$
[\eta]=\frac{K}{100 d}
$$

For spherical particles, $K=2.5$. Values of $K$ as a function of axial ratio for oblate and prolate spheroids of revolution have been calculated by Mehl, Oncley, and Simha [11].

Calculation of the micellar weights from the lightscattering data was done with the simple Debye equation

$$
H \frac{C_{m}}{\tau}=\frac{1}{M}+2 B C_{\mathrm{m}}
$$

where

$$
H=\frac{32 \pi^{3}}{3} \cdot \frac{n_{0}^{2}(\Delta n / \Delta c)^{2}}{\lambda^{4} N}
$$

Once again $C_{\mathrm{m}}$ is the concentration of micelles, although this time in grams per milliliter. $M$ is the micellar weight. $B$ is an interaction constant; its significance in solutions of charged colloidal particles has been discussed [12]. $\tau$ is the turbidity due to the presence of micelles. It is the observed turbidity of a solution minus the turbidity at the critical micelle concentration. The refractive index of the solvent is $n_{0} .(\Delta n / \Delta c)$ is the refractive-index increment of the solutions. $\lambda$ is the vacuum wavelength of the light used, $436 \mathrm{~m} \mu . \quad N$ is Avogadro's number.

In the case of dodecylamine hydrochloride at sodium chloride concentrations above $0.20 \mathrm{M}$, the micelles are large enough to scatter asymmetrically. This means that the scattered intensity observed at $90^{\circ}$ is not indicative of the turbidity of the solutions and that the micellar weight calculated therefrom is in error. Because no dissymmetry corrections were applied, turbidities for these systems are not given in table 1. An estimation of the intrinsic dissymmetry has been made, and these values are given. The micellar weights listed are approximations calculated from the data as if there were no dissymmetry effects.

Plots of the intrinsic viscosity and micellar weight as a function of sodium chloride concentration for each of the detergents investigated are given in figures 4,5 , and 6 .

Considering both $M$ and $[\eta]$ over the total range of sodium chloride concentrations covered, each of the three detergents investigated shows different behavior. However, considering only the dependence of $[\eta]$ on sodium chloride concentration up to about $0.05 M$, the three detergents behave similarly, i. e., the intrinsic viscosity decreases as sodium chloride is added. This is the same behavior as that exhibited by sodium dodecyl sulfate, and reflects the diminution

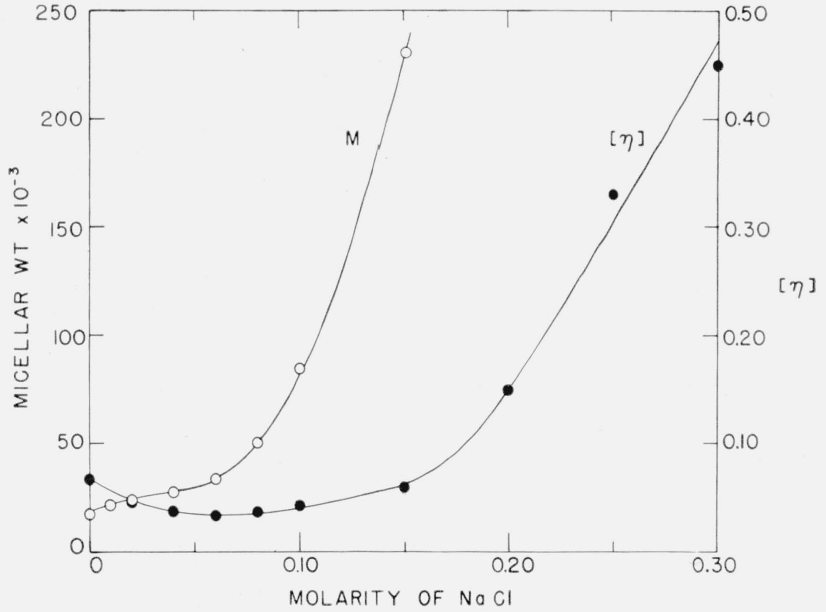

Figure 4. Dependence of the micellar weight (O) and intrinsic viscosity (-) of dodecylamine hydrochloride micelles on the concentration of sodium chloride in aqueous solutions.

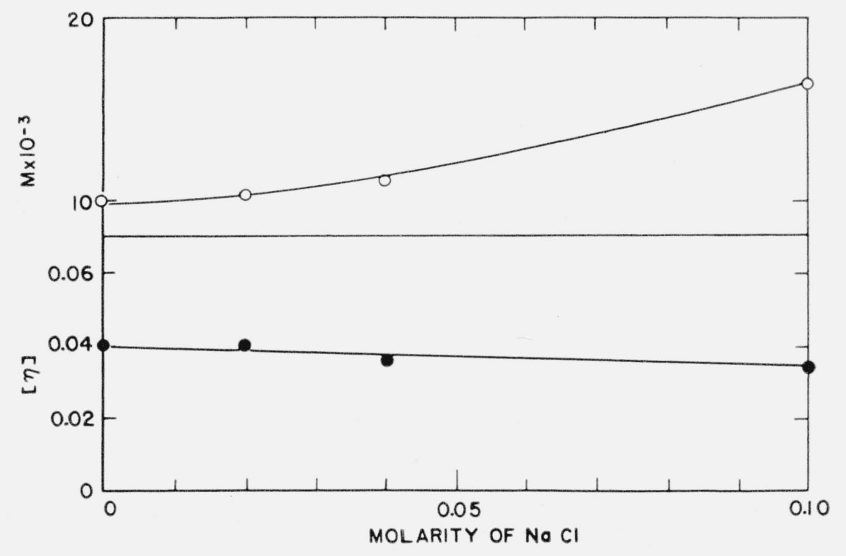

Figure 5. Dependence of the micellar weight ( $\bigcirc)$ and intrinsic viscosity (-) of dodecyltrimethylammonium chloride micelles on the concentration of sodium chloride in aqueous solutions.

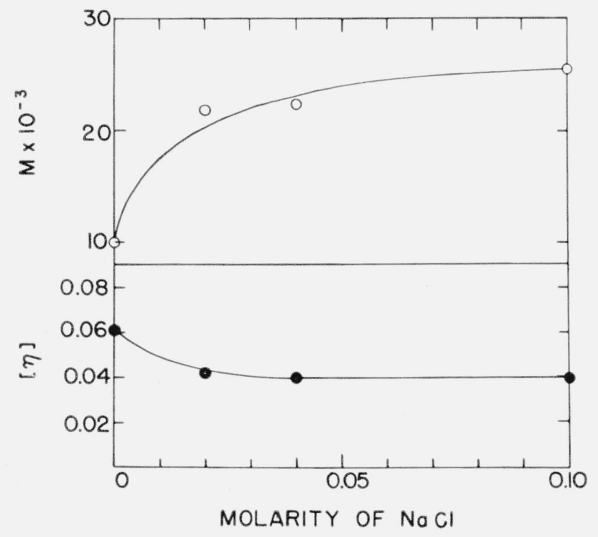

Figure 6. Dependence of the micellar weight $(\bigcirc)$ and intrinsic viscosity (-) of tetradecyltrimethylammonium chloride micelles on the concentration of sodium chloride in aqueous solutions. 
of electroviscous effects caused by the high degree of ionization of the micelles. ${ }^{2}$

At a concentration of about $0.05 M$ sodium chloride, the electroviscous effect appears to be virtually eliminated. An interesting result is that the electroviscous effect for dodecyltrimethylammonium chloride is substantially less than that for dodecylamine hydrochloride or tetradecyltrimethylammonium chloride. The inference is that the micelles of dodecyltrimethylammonium chloride carry a lower charge than the micelles of the other two detergents. However, no explanation for this can be given at this time.

The minimum value of $[\eta], 0.033$ to 0.040 , obtained with all of the cationic detergents is to be compared with the value 0.035 obtained with sodium dodecvl sulfate. All of these values are consistent with the concept of spherical hydrocarbon micelles having a density of about $0.75 \mathrm{~g} / \mathrm{ml}$. According to eq 2, $[\eta]$ for such micelles would be about 0.033 . The differences among the intrinsic viscosities observed may reflect a difference in the density of the micelles in each case.

At higher concentrations of sodium chloride (up to $0.1 M$ ) the intrinsic viscosities of the two quaternary salts remain constant in spite of the increasing micellar weight. This merely serves to emphasize that small micelles (those containing about 50 to 150 detergent molecules), regardless of their precise shape, will of necessity have axial ratios close to unity and will behave hydrodynamically as spheres. The growth of the micelles on the addition of neutral electrolyte has been interpreted [5] as resulting from a reduction in the work necessary to bring together the ionic heads of the detergent molecules when a micelle is formed.

With dodecylamine hydrochloride the addition of sodium chloride beyond $0.05 M$ results in rapid growth of the micelles. This is made evident not only by the micellar weight but also by the intrinsic viscosity, which increases greatly. Once again it is evident that the light-scattering method is much more sensitive for measuring the growth of the micelles than is the viscosity method, particularly up to micellar weights of about 250,000 . The high values of $[\eta]$ that are obtained as $M$ increases are additional evidence for the high asymmetry of large micelles. The quantitative correlation between micelle dimensions calculated from the viscosity data and from the light-scattering data is poor. For example, at a sodium chloride concentration of $0.3 M,[\eta]=0.45$, and the intrinsic dissymmetry is close to 1.40. Taking a rodlike micelle as being the most likely [13], one calculates from the intrinsic dissymmetry [14] a length of about 1177 A. Approximating the rod to an elongated ellipsoid of revolution whose minor axis is equal to the extended length of a

${ }_{2}^{2}$ For a brief discussion of the electroviscous effect, see Colloid science, edited by H. R. Kruyt, vol. I, p. 348 (Elsevier Publishing Co., New York, N. Y., 1952). dodecvlamine hvdrochloride molecule, $20 \mathrm{~A}$, one calculates [11] a length of $720 \mathrm{~A}$ from $[\eta]$. It must be mentioned, however, that for this system both $Z$ and $\left(\eta_{\mathrm{rel}}-1\right) / C_{\mathrm{m}}$ are rapidly changing functions of $C_{\mathrm{m}}$ as $C_{\mathrm{m}} \rightarrow 0$. Hence the probable errors in both the intrinsic dissymmetry, $[Z]$, and in the intrinsic viscosity, $[\eta]$, are quite large $( \pm 10$ to $15 \%$ would not be unreasonable). In addition, with such large asymmetric micelles, one must consider the possibility of non-Newtonian flow. This was not investigated.

The rapidly increasing size of the dodecylamine hydrochloride micelles is probably the first step in the salting-out process. On standing at $23^{\circ} \mathrm{C}$, visible crystals were observed in 0.5 -percent solutions of the detergent in a $0.04-M$ sodium chloride solution. At $30^{\circ} \mathrm{C}$ it was possible to prepare 1-percent solutions of the detergent in sodium chloride solutions as concentrated as $0.30 \mathrm{M}$, but at higher salt concentrations it was insoluble. The quaternary salts, being inherently more soluble, show no such effects in this range of sodium chloride concentrations.

In the case of tetradecyltrimethylammonium chloride in distilled water, because it has a low critical micelle concentration, it was thought that it might be possible to observe dissymmetries of less than unity, as discussed by Doty and Steiner [14]. Such effects should exist, being the result of external interference arising from the nonrandom fluctuations in concentration of the highly charged micelles. However, dissymmetries of less than unity were not observed. Apparently, even in this case, in which the shielding electrolyte is unaggregated detergent at its critical micelle concentration $(0.0043 \mathrm{M})$, shielding is sufficiently good to permit random fluctuations, at least up to $C_{\mathrm{m}} \sim 1 \mathrm{~g} / \mathrm{dl}$.

\section{References}

[1] J. N. Phillips and K. J. Mysels, J. Phys. Chem. 59, 325 (1955).

[2] L. M. Kushner and W. D. Hubbard, J. Colloid Sei. 10, 428 (1955).

[3] L. M. Kushner, B. C. Duncan, and J. I. Hoffman, J. Research NBS 49, 85 (1952) RP2346.

[4] D. Stigter and K. J. Mysels, J. Phys. Chem. 59, 45 (1955).

[5] P. Debye, Ann. N. Y. Acad. Sci. 5̈1, Art. 4, 575 (1949).

[6] K. J. Mysels, J. Phys. Chem. 58, 303 (1954).

[7] P. P. Debye, J. Appl. Phys. 17, 392 (1946).

[8] L. M. Kushner, J. Opt. Soc. Am. 44, 155 (1954).

[9] H. M. Smith and cooperators, Anal. Chem. 22, 1452 (1950).

[10] M. L. Corrin and W. D. Harkins, J. Am. Chem. Soc. 69, 683 (1947).

[11] J. Mehl, J. Oncley, and R. Simha, Science 92, 132 (1940).

[12] P. Doty and J. T. Edsall, Advances in protein chemistry, vol. VI (Academic Press Inc., New York, N. Y., 1951).

[13] P. Debye and E. W. Anacker, J. Phys. \& Colloid Chem. 55, 644 (1951).

[14] P. Doty and R. F. Steiner, J. Chem. Phys. 20, 85 (1952).

Washington, D. C., December 6, 1956. 